\title{
Dos cartas, dos informantes, dos tradiciones
}

\author{
Wellington Castillo Sánchez \\ Universidad Nacional de Trujillo \\ ccyculturavallejo@yahoo.es
}

\begin{abstract}
Mis tradiciones, más que mías, son de ese cronista que se llama pueblo (...) Mía es, sin duda, la tela que las viste; pero no el hecho fundamental. Yo no invento, copio. Soy un pintor que restaura y da colorido a cuadros del pasado.
\end{abstract}

(Carta de Palma a Carlos Toribio Rabinet del 18 de enero de 1878)

\section{Resumen}

El presente trabajo trata de la búsqueda, el hallazgo y la exhibición de dos cartas escritas a Palma por dos informantes de la ciudad de Huamachuco: Nicolás Rebaza Cueto y Francisco Moreno Azcate, en cuyos textos se encuentran la fuente escrita de las tradiciones Los brujos de Shulcahuanga, y la III parte de Los buscadores de entierros. Se hace la exégesis a los textos literarios de ambas tradiciones confirmando los hallazgos de los estudios y de la amplia crítica que se ha hecho a la vida y obra del Patriarca de nuestra letras, y, en el caso de Los brujos de Shulcahuanga, en los alcances de la crítica, muchas conclusiones son diferentes a las que han llegado algunos autores, lográndose con creces los objetivos de los encuentros denominados "Re-visión de las Tradiciones".

Palabras clave: Cartas, informantes, Tradiciones, fuentes, exégesis.

\begin{abstract}
The present work deals with the search, discovery and exhibition of two letters written to Palma by two informants from the city of Huamachuco, Nicolás Rebaza Cueto and Francisco Moreno Azcate, whose texts include the written source of the Traditions "The witches of Shulcahuanga", and the third part of "The burial seekers". The exegesis is done to the literary texts of both traditions confirming the findings of the studies and extensive criticism that has been made to the life and work of the Patriarch of our letters, and, in the case of "The witches of Shulcahuanga", in the reaches of the critique, many different conclusions to which some authors have arrived, achieving more, the objectives of the meetings denominated "Re-vision of the Traditions".
\end{abstract}

Keywords: Letters, informants, Traditions, sources, exegesis. 


\section{Wellington Castillo Sánchez}

Dramaturgo, ensayista, poeta, promotor cultural. Actualmente es docente de Pre y Postgrado de la Universidad Nacional de Trujillo. Premio Nacional de Teatro Sebastián Salazar Bondy en 1989. Ha publicado poesía, ensayos y narrativa. 
En la Biblioteca Virtual, Nuestras Colecciones: Ricardo Palma, de la Biblioteca Nacional del Perú, se están exhibiendo, entre otras, dos cartas remitidas a Ricardo Palma ${ }^{1}$. Una de ellas, de Nicolás Rebaza Cueto, escrita en la ciudad de Trujillo, con fecha 1 de enero de 1887, en respuesta, según se ve del propio texto, a una carta que le escribió Palma a fines del año anterior pidiéndole que le informara del expediente del proceso seguido a los indígenas sublevados en Huamachuco, 1818-1819, del cual habían hablado, años antes, en Lima, ocasión en la que el tradicionista le pidió lo enviase para que se archive y conserve en la Biblioteca Nacional. En la carta, además de exponerle varios asuntos que no es necesario referir, Rebaza Cueto "le da razón" del proceso, lamentando que había desaparecido y, a cambio, le expone los datos y hechos de dicha sublevación sobre los cuales el Maestro escribe la Tradición Los Brujos de Shulcahuanga. La otra carta es de Manuel Moreno, escrita y remitida a Palma desde Huamachuco, con fecha 2 de febrero de 1891, en la cual le da a saber su entusiasmo por la lectura de dos Tradiciones, una de las cuales le hace recordar "a la presumida y colosal fortuna de una huaca", la graciosa anécdota del tesoro enterrado de Orgopú que sintetiza y narra, y toma Palma para elaborar la parte III de la Tradición Los buscadores de entierros.

\section{Exégesis de la Tradición Los brujos de Shulcahuanga y de la parte III de la Tradición Los buscadores de entierros}

La exhibición de estas dos cartas y el conocimiento de sus contenidos, pertinentes al trabajo literario del gran tradicionista, los datos y hechos del Shulcahuanga y la narración de la

l Estas cartas fueron encontradas hace dos años en los archivos de la Biblioteca Nacional del Perú por Aladino Carbajal, huamachuquino, quien conociendo que estábamos en la búsqueda de las fuentes de las Tradiciones mencionadas, gentilmente nos hizo llegar las copias. En el año 2015 publicó Cartas de Nicolás Rebaza a Ricardo Palma. 
anécdota sobre el supuesto tesoro enterrado de Orgopú, generan la necesidad de hacer la exégesis de los textos literarios de las tradiciones mencionadas, una nueva, en el caso de Los brujos de Shulcahuanga, más conocida y tratada por el tema de carácter histórico preindependentista que encierra, cuyo análisis literario, valoraciones y crítica se han hecho sin tener en cuenta su fuente escrita ${ }^{2}$. La atención que deben merecer estos textos, relacionados con los de las Tradiciones, nos lleva a plantear un método de exégesis abierto, flexible, holístico, que debe tomar en cuenta los componentes externos e internos del proceso de escritura, congruente, además, con la naturaleza de la propuesta literaria de Palma: la fusión/separación de lo objetivo y lo ficcional y, además, dimensionar y valorar cómo, de los primeros, escritos prosaicos de datos y hechos, aquella materia prima, siguiendo un plan de escritura, la eleva a la dignidad de una obra de arte, estética, configurada en la creación de un género literario de estilo único.

La tarea exegética involucra, entonces, varios aspectos de la escritura palmiana: las fuentes y los informantes de las dos Tradiciones ambientadas en la Región La Libertad relacionadas con la personalidad del autor, como elemento externo; con lo concerniente a su narrativa; con la determinación, en lo posible, de los límites entre lo histórico y lo literario, con la "proporcionalidad", que suele ser variable y no del todo clara (Huárag, 2004: 51) y con su estilo, que logra la unidad de lo real histórico con lo literario a través de un lenguaje cargado de humor irónico, jocoso, satírico y burlón, elementos de su estructura interna.

Los resultados de esta tarea tal vez confirmen, en unos casos, los hallazgos de los estudiosos y críticos, pero, en otros, de acuerdo a

2 Mencionamos a los autores Isabelle Tauzin Castellanos, Virgilio Roel Pineda, Augusto Tamayo Vargas y Leonor Segermann Bustinza. 
lo que aparezca de la crítica, posiblemente se amplíen, enriquezcan y enmienden juicios, señalamientos y reproches vertidos a la obra y al Maestro; logros que se inscriben alentadoramente en los objetivos que buscan estos encuentros Palmistas.

Pasemos a desarrollar estos aspectos con su debida amplitud y pertinencia.

\section{Fuentes e informantes de las Tradiciones}

En nuestro aporte sobre las Tradiciones ambientadas en la Región de la Libertad ${ }^{3}$, señalamos que las fuentes de la Tradición Los brujos de Shulcahuanga, reveladas por Palma en la parte II del texto, no eran definitivas, solamente aproximadas. Mayor problema ha sido determinar la fuente de la parte III de la tradición "Los buscadores de entierros", porque el Maestro apenas la insinúa; por ello, la consideramos referencial.

Ahora bien, la exhibición de las dos cartas referidas y el conocimiento de sus textos pertinentes permiten esclarecer, precisar y modificar aquello que ya habíamos planteado sobre el tema: la carta de Nicolás Rebaza Cueto, el "caballero de Trujillo", confirma por un lado que la fuente remota escrita de la tradición Los brujos de Shulcahuanga fue el expediente "de 100 y tantas fojas" que contenía el proceso judicial seguido a los sublevados del Shulcahuanga, cuyo legajo lo conservó hasta 1885, pero que, desgraciadamente, como da cuenta al Maestro, desapareció en el saqueo de su vivienda perpetrado por D. Tomás R. y Flores, como secuela de uno de los combates que se libró en esta ciudad ${ }^{4}$. Y los datos y hechos contenidos en

3 Ver, Sartenazos que duelen o tiznan. Tradiciones de Ricardo Palma de la Región La Libertad, 2012, Edit. CEA.

4 Se trata de la batalla de Trujillo entre "azules" y "rojos" en la guerra civil entre Iglesias y Cáceres (1884-1885). Rebaza Cueto, según testimonia en su carta, era simpatizante de Iglesias. 
esta carta, memorizados "desde su niñez" por el informante, las "apuntaciones" en denominación de Palma, fueron la fuente directa de la Tradición. No podremos determinar, en cambio, cuáles fueron los documentos que Palma leyó para decir que el extracto que escribe en la parte II de la Tradición lo elabora, además, "ateniéndose a su memoria"; pues por otra carta de Rebaza Cueto, escrita y remitida desde Trujillo el 25 de noviembre de 1893, ya no es posible corroborar que posiblemente se trataba de sus apuntes sobre la independencia de La Libertad que más tarde los publicó como los Anales del Departamento de La Libertad en la Guerra de la Independencia, o simplemente Anales, en 1897, con prólogo escrito especialmente por Palma. La tradición sobre los acontecimientos de Shulcahuanga, como sabemos, se publicó en Tradiciones de la Patria Vieja, El Ateneo de Lima, Tomo III, 1887, el mismo año que recibió la carta.

Queda evidenciado, asimismo, que la carta de Manuel Moreno, en la cual le narra la anécdota del tesoro enterrado en el pago de Orgopú, Huamachuco, es la fuente escrita de la parte III de la Tradición Los buscadores de entierros. El texto pertinente de esta carta constituye la primera escritura, el primer testimonio y la única versión, posiblemente, de lo que sucedió en realidad, en los tiempos que finalizaba la colonia.

De manera que a la relación de los informantes y de las ciudades o regiones del país que tuvo Palma para escribir las Tradiciones debemos agregar al Dr. Nicolás Rebaza Cueto, Magistrado e historiador y, a don Manuel Moreno Azcate, quien fue Notario Público, ambos naturales de la ciudad de Huamachuco ${ }^{5}$.

5 El Sr. Francisco Moreno Ruiz, tataranieto de Manuel Moreno, nos ha facilitado el apellido del informante y la función que desempeñó en la ciudad de Huamachuco. 


\section{De las fuentes al texto literario de las Tradiciones}

\section{La primera carta: Los brujos de Shulcahuanga}

De la lectura comparativa de ambos textos, el de la fuente y el literario, podemos observar que Palma toma de "las apuntaciones" casi en su totalidad los datos y hechos precedentes y posteriores a la sublevación del Shulcahuanga, que Rebaza Cueto narra e informa a su manera y en base a su memoria para escribir la Tradición. Es obvio que los ha procesado; ha dejado de lado, aumentado, cambiado, añadido y cuantificado uno que otro dato o hecho; ha caracterizado algún personaje; los ha reordenado, seleccionado, escrito en su estilo y, finalmente, agrupado en dos niveles narrativos unidos e interrelacionados y, posiblemente, antes de darlos por terminados, revisado una y otra vez, pacientemente, como solía hacer al escribir su obra. (Tanner, 2005: 18)

Yendo de uno a otro texto, cuando lo requiera la exégesis, la exploramos a continuación.

\section{Parte I}

Es el bloque de nivel narrativo literario, la parte verosímil de los acontecimientos de la sublevación. Se inicia con la siguiente descripción:

En la cadena que forma la cordillera de Otuzco a Huamachuco se ve un cerro elevado y de forma cónica, el cual desde los tiempos incásicos se conoce con el nombre de Shulcahuanga.

Terminaba el año de 1818 cuando entre los ochenta mil indígenas que componían la subdelegación de Huamachuco, 
tomó creces el rumor de que la cumbre del Shulcahuanga era habitada por brujos y brujas.

En efecto, desde la parte llana veíanse bustos que iban y venían, y aún en algunas noches, llamaradas y luces de cohetes voladores. (Palma, 1961: 932)

Apreciamos de inmediato la impronta literaria de Palma: toma los datos iniciales sobre la ubicación, forma, origen del nombre del cerro, año de los hechos, a los cuales añade otros, anotados líneas adelante en el texto de la carta, respecto a la cantidad de población indígena de Huamachuco y que la "vulgaridad" e "ignorancia" propalaron entre la gente respecto a que los del Shulcahuanga eran brujos porque hablaban con el diablo, que ardió a la vista de ellos y cuya aparición en el cerro fue como un rayo o centella. El notable tradicionalista elabora una entrada sencilla, precisa y magistral que nos lleva por un paraje remoto de la sierra del Perú, envuelto en una atmósfera misteriosa configurada con la información de que entre los ochenta mil indígenas que poblaban Huamachuco crecía "el rumor" de que en la cumbre del Shulcahuanga habitaban brujos y brujas, y que algunas noches en el cerro se veían "llamaradas y cohetes voladores".

El Maestro, desde el inicio de la Tradición, introduce la nota de leyenda mágica; la creencia y superstición del pueblo de que brujos y brujas habitaban el Shulcahuanga. ¿Por qué lo hace? Además de conferirle sabor humorístico, esta atmósfera envuelve y aparentemente desfigura la historia, distorsionando las connotaciones y significaciones de una sublevación de carácter preindependentista.

Por otro lado, para su tadición Palma tomó la "intra historia”, es decir, la historia menuda, no la gran historia. Por eso recogió ese "rumor" que envolvía la memoria de los hechos, los personajes 
y sucesos del Shulcahuanga, la expresión, los decires, las ideas y creencias del pueblo. A partir de esta entrada se narran los acontecimientos propios de la sublevación que podemos leer en la Tradición (Ibíd., p. 933).

La narración ficcional, limpia, ligera, elegante, se matiza con elementos de pura cepa palmiana. Por ejemplo, la inclusión de pasquines. Elemento que concierne al uso y manejo del lenguaje popular, preciso, humorístico, de alta elaboración y pulimento, que como él mismo decía está a la vez profundamente ligado a la evocación y representación de los hechos y sucesos de una sublevación que se narra. Estos pasquines, en una lectura aislada de la fuente, dan la impresión de que fueran los originales contenidos en el expediente del proceso, transcritos a la narración. Solo ahora sabemos que no es así. Son fruto del talento, el ingenio y la creatividad de Palma.

Con la finalidad de corroborar lo afirmado veremos solo el segundo pasquín de la Tradición, dirigido al sacerdote Soto y Velarde, que se construye tomando el dato del informante de que lo amenazaban escribiéndole: "Ay Soto, Sotito, te he de quitar el quinto pellejo como a cabrito". (Carta de Rebaza Cueto).

En lenguaje sencillo, popular y apropiado, expresando -quién puede dudarlo-, su anticlericalismo y jocosidad, le redondea al curita el siguiente pasquín:

No se meta en honduras

padre vicario

y ocúpese tan solo

de su breviario.

iSoto! iSotito!

ya te desollaremos

como a cabrito. 
Palma utiliza apropiadamente el modo narrativo dramático o teatral, estrategia con la cual crea ambientes y atmósferas adecuadas para describir y enlazar acciones de los personajes. (Bazán, 200 1: 169). En el párrafo que sigue, intensifica y otorga pleno valor al hecho propiamente épico de la sublevación, el sitio del Shulcahuanga cuando se enfrentan los dos personajes principales, el líder de la sublevación José Luz de la Verdad y el subdelegado Manuel Fernández Llaguno:

Apareció entonces sobre la cima del Shulcahuanga un hombre que arengó a los sitiadores en estos términos: -Yo soy José Luz de la Verdad y os requiero para que matéis a los patrones tiranos y a los curas esquilmadores de las ovejas. Esta tierra es nuestra (...) iAbajo la tiranía! iViva la libertad! (...)

-iA escalar el cerro! iMatar a ese insurgente! -gritó el subdelegado. (Ibídem).

Las acciones descritas y los parlamentos, apenas bocetados e insinuados en la relación de la carta, Palma los eleva y enriquece con mayores significaciones propias de una gesta. La arenga que pronuncia José Luz de la Verdad, como podemos apreciar, es propia de un sublevado, de un alzado independentista. Aún más, valoremos el siguiente párrafo:

Parece incré́ble, pero entre los sitiadores, que eran doscientos españoles y más de quinientos indios, peones de las haciendas, hubo algo como una oleada de simpatía por las toscas frases del orador. (Ibíd., p. 934).

La alusión a esta "oleada de simpatías" que produce el discurso de José Luz de la Verdad, en los sitiadores, no se señala en "las apuntaciones" del informante. ¿De dónde las toma Palma para evidenciarlas en el texto? Sin duda, de su propia creación; 
son, a no dudar, producto de sus simpatías y convicciones, que las expresa en niveles narrativos donde de manera breve opina comenta, juzga, valora, etc. Aquí, Palma, construye un nivel narrativo para dar razón y justificación a la causa de la conspiración de los del Shulcahuanga. La acción épica culmina, coherentemente, con la descripción de una imagen espectacular de la muerte, del sacrificio digno, diríamos, de un líder que pese a todas las desventajas se alzó en contra de un sistema injusto:

Sonaron algunos disparos de fusil, y un hombre vino rodando desde la altura.

Era el cadáver de José Luz de la Verdad.

La gente que lo acompañaba puso bandera blanca y se rindió a la autoridad. (Ibídem).

La narración ficcional de Los brujos de Shulcahuanga está intensificada por una serie de palabras de uso común y a veces de procedencia latina, altamente literarias. Mencionaremos algunas: "socaliñas parroquiales", "sermoneaba a los indios", "con pasquines (...) eran agasajados los principales realistas", "se desazonó ante la flema”, "poner en ebullición a los indios", "vio las cosas con prisma distinto”, “...que procediese virga férrea”.

\section{Parte II}

Es la "digresión" el texto objetivo de los datos, de los personajes, de los hechos históricos y de las consecuencias de la sublevación, la crónica de la Tradición que Palma escribe con la finalidad de ofrecer al lector un "extracto" de lo que contenía dicho proceso.

Confrontado el texto de la crónica con el de "las apuntaciones", podemos observar que Palma toma los datos de la información que considera objetivos, históricos, adecuados para una crónica, 
y como se ha señalado, los reordena, ubica e inicia la escritura dando cuenta de la existencia del expediente del proceso seguido a los prisioneros, en base a la referencia del informante; luego, presenta los demás datos de este bloque. (Ibídem).

Un aspecto importante sobre la crónica la elabora a base de esas "apuntaciones", fuente que ha servido a su autor para trabajar la parte literaria. Aunque optó por lo literario era también historiador, por lo que sabía perfectamente que las “apuntaciones" escritas por Rebaza Cueto, basándose en su memoria, eran objetivamente débiles en la verdad histórica. Sin embargo, él confió en el relato memorizado del amigo y le otorgó status de verdad histórica. ¿Por qué lo hizo? Nos parece que obró así por la necesidad de ubicar la digresión, los hechos objetivos, históricos, la crónica como elemento imprescindible en la estructura de la Tradición. Pero en este bloque, escribe varias sutilezas que podrían pasar sin darles importancia y significación alguna si es que no las atendemos, entendemos y valoramos debidamente en la exégesis, a partir de la fuente de la Tradición.

Por ejemplo: el rasgo étnico social que le da a José Salinas. A diferencia del informante, que ubica al líder dentro del grupo de "indígenas" que desde luego sabía leer y escribir, Palma lo describe como "mestizo... leído y escribido", descripción que nos parece no es simple. Salinas desempeñaba trabajos y oficios diferentes a los que hacían los llamados indios de las haciendas; había aprendido a leer y escribir; aún más, había sido iniciado en el latín por ser sacristán de iglesia. En la visión que tenía Palma del Perú de su tiempo ya no podía considerarlo indígena; el calificativo de mestizo que le da alude a su ubicación dentro de un grupo social diferente al de los indios, condición social que lo avala, además, como líder de una sublevación, de una gesta que tuvo caracteres de un movimiento preindependentista. 
Otra sutileza tiene que ver con el señalamiento de las causas de la sublevación. Palma afirma que "quisquillas y malos tratamientos de su patrón Noriega" motivaron que Salinas fugara de la hacienda Chota, se refugiara en las alturas del cerro Shulcahuanga y encabezara una conspiración contra el rey. Calificada de esa manera, da la impresión que no sería una buena causa. No es así. Es una causa humana, social e históricamente válida que explica y justifica su reacción natural, valiente, riesgosa, contra los abusos de un sistema injusto, indigno y de explotación del hombre por el hombre. Es una causa que sustenta el movimiento de nuestra independencia, tan importante como la propia ideología que solamente asimiló una élite.

Se dan asimismo sutilezas de carácter cuantitativo tan atinadas que nos hacen ver que Palma buscaba ofrecer una idea de las proporciones del movimiento. En "las apuntaciones", el informante estima que solo "dos o tres familias apellidadas Salinas" fugaron de Chota y se refugiaron en el cerro Shulcahuanga; el autor considera que fueron "sesenta" las personas que siguieron al rebelde, entre "deudos" y amigos; es decir, en la lógica de quienes y cuantos podían haberse unido a una causa riesgosa para sus vidas, número que es coherente con la cantidad de "cincuenta", también ficcional, que rodearon a José Salinas en la refriega del sitio del Shulcahuanga en la cual, en otra cifra inventada señala que los sitiadores del cerro eran "doscientos" "españoles americanos" y más de "quinientos indios", peones de haciendas. Al igual que la causa, válida históricamente, estas cifras y la composición de los grupos contrincantes, tan acertadas en la narrativa, no están lejos de la realidad. Basta recordar lo que señalan los historiadores respecto a la proporción y composición social de los ejércitos realistas de los y libertadores que se enfrentaron por nuestra independencia. 
Como dato histórico, Palma ratifica la afirmación asentada en el bloque ficcional de que era voz pública que "los conspiradores celebraban conciliábulos", con la descripción: "Para los del pueblo, los del Shulcahuanga quedaron, no en concepto de conspiradores, sino en el de brujos, puesto que declaraban estar en tratos y contratos con el diablo patriota". Además de la forma delicada en que este dato, tomado de las referidas "apuntaciones", lo ubica en el texto, la idea es psicológica, social y culturalmente válida; supera el aparente desmerecimiento de la calidad de sublevados del Shulcahuanga; en el tono humorístico popular se les podía llamar y considerar así, brujos; inclusive en una actitud de simpatía se podía encubrir conscientemente la verdadera actividad a la que se entregaban los sublevados. Pensemos, además, en la siguiente referencia anotada en la carta por Rebaza Cueto: "Evacuadas todas las declaraciones el Sub Delegado parece hizo poner en libertad a los indígenas, aunque no constaba en el proceso...", que, en la crónica, Palma lo describe así: "Pasando tres meses y no sacando el subdelegado nada en limpio, se decretó la libertad de los presos". ¿Qué podemos pensar de esta situación de los sublevados? ¿Por qué no fueron encarcelados? ¿Por qué fueron liberados tan fácilmente? Por otro lado, la sutileza de Palma de calificar a la persona con quien se entendía José Salinas como "diablo patriota", además de la carga de humor que contiene es muy rica y sugerente en connotaciones populares: bien se le podía tildar como diablo a un patriota.

Se dan también algunas delicadezas que debemos señalar: el informante vierte palabras y frases que revelan prejuicios y desvaloración a personajes y a hechos de la sublevación, algunas de él, otras atribuidas a las autoridades representadas en la Tradición, tales como: "sabía leer y escribir, no obstante ser indígena", "sirviente de mano", "escribir proclamas en un lenguaje tosco, disparatado", "prosa disparatada y verso", "la 
vulgaridad en Huamachuco y otros pueblos (...)”, “(...) Todo esto lo propaló la ignorancia”, “(...) de niño me entretenía en leerlo, por la figuras y disparates que contenía”, “(...) los papeles disparatados podían ser obra de algunos borrachos o necios" (Ver carta de Rebaza Cueto). Palma tomó estas frases para elaborar la Tradición, pero las elevó a su estilo, haciéndolas elegantes y confiriendo limpieza a la narración.

Dato de crónica que toma de esos aportes es la presencia de dos personajes importantes, uno más que el otro, de nuestra historia: José Luis de Orbegoso y José Faustino Sánchez Carrión. A diferencia de Rebaza Cueto quien afirma que en el expediente había, entre las declaraciones del año 18, la del señor D. Luis José de Orbegoso, dueño de Chuquisongo" un hombre de aspecto europeo que "pudo ser el dueño del cerro y que hacía escribir a Salinas", y la de que su paisano Sánchez Carrión "se hallaba por entonces en Huamachuco obligado por el Virrey a salir de Lima por revoltoso". Palma habla de las "vagas presunciones" respecto a la participación en la sublevación de estas personalidades de nuestra historia. Estos indicios pueden convertirse en un apasionante tema de carácter histórico para conocer, aunque fuese aproximadamente, al personaje o a los personajes independentistas que coordinaron con José Salinas la sublevación del Shulcahuanga.

La crónica finaliza con un importante aporte histórico que también está señalado en los datos de Rebaza Cueto: San Martín y el Congreso de 1823, "teniendo en cuenta la tentativa revolucionaria de 1919", otorgaron a Huamachuco, que hasta entonces era solo cabeza de provincia, el título de "muy noble y fiel ciudad". Gestor de esta acción digna de gobierno fue, sin duda, Sánchez Carrión; y, el título "muy Ilustre y Fiel Ciudad" y los años "1821 y 1822" constan en el decreto correspondiente. (Peña Rebaza, 2016: 104-105) 


\section{La segunda carta. De la anécdota del tesoro enterrado de Orgopú a la parte III de la Tradición Los Buscadores de entierros.}

Los sucesos de la anécdota de la supuesta riqueza enterrada en Orgopú, Huamachuco, que Manuel Moreno da a conocer en su carta a Palma, están expuestos con cierto orden en párrafos espaciados tipo telegrama, notándose el esfuerzo del informante de remarcar las partes graciosas del hecho. Suponemos que Palma no tomó todo el material que tenía o llegaba a sus manos para "tradicionarlo". En el caso de la anécdota de Orgopú, pensamos que encontró los suficientes méritos para elevarla a una obra de arte, a una Tradición: el tema de tesoros escondidos; las situaciones jocosas, en especial la de los calzones (pantalones) de Sosa Vergaray, uno de los protagonistas del hecho; el resultado de la búsqueda de dicho tesoro que fue un fiasco, final que calza perfectamente con la situación donde Palma ubica burlonamente a los buscadores de entierros que solo sacan "lo que el negro del sermón: la cabeza caliente y los pies fríos" (Palma, 1961: 927), amén de un suceso anecdótico ocurrido en una región y una ciudad entonces remota y de renombre, Huamachuco, que fortalecía la idea de representar a todo el Perú en su proyecto literario.

Siguiendo su plan escritural reordena, descarta, incrementa situaciones, acciones, circunstancias; crea y recrea atmósferas, desafecta y selecciona el material con el cual logra un solo bloque ficcional. Es decir: una narración ligera, amena, elegante y humorística, que se ubica en la parte III de la Tradición. Al igual que en Los brujos de Shulcahuanga, la inicia con un párrafo descriptivo, sencillo y sugerente, siguiendo el orden de los datos y hechos de la carta: la ubicación del lugar, el año en que se produjo la anécdota, el nombre de los protagonistas principales y la circunstancia tan pintoresca de Sosa Vergaray, uno de los personajes protagonistas, que ve fuegos fatuos en una huaca, 
señal de riqueza enterrada, en momentos que a mitad de la noche satisfacía una necesidad orgánica.

Orgopú, en la provincia de Huamachuco, era en 1817 un pequeño pago o chacra de un mestizo llamado Juan Príncipe. Hacia el lado fronterizo del bosque de Collay, había otra chacrita perteneciente al indígena Juan Sosa Vergaray. Acontecióle al último tener que abandonar a medianoche la cama y salir al campo (...) y mientras satisfacía ésta fijó la vista en un cerrillo o huaca (...) y viólo iluminado por vivísima llama que de la superficie brotaba. (Ibíd., p. 929).

Una sutileza en esta parte es la calificación de "mestizo" y de "indígena" que da a uno y otro personaje. Aparentemente sin importancia, porque en adelante no le da connotaciones mayores, es sin embargo un detalle de representación de tipos que pertenecen a una sociedad estratificada en la que todos somos iguales tratándose de tesoros o riquezas, aunque fuesen escondidas.

En el corto párrafo que sigue, Palma asienta el motivo de los sucesos en la creencia de que allí donde hay depósito de metales o de osamenta y nada tienen de maravilla los fuegos fatuos, no solo es cosa de la "preocupación popular" sino de la ciencia. No es una digresión; el bloque agota la recreación de la anécdota; la digresión la encontramos en la parte inicial de la Tradición. (Ibíd., p. 927-928).

Luego, prosigue la narración destacando el gracioso rol que juegan los calzones de Sosa Vergaray:

A Sosa Vergaray se le ocurrió que Dios lo había venido a ver, deparándole la posesión de un tesoro (...) y no teniendo otra señal que poner en el sitio donde percibiera el fuego fatuo, dejó los calzones, regresando a su casa en el traje de Adán. (Ibíd., p. 929). 
La denominación de "calzones", equivalente a pantalones, tiene en la narración de la carta cierto rol jocoso. Palma acentúa el gracejo y, con lenguaje humorístico, enriquece el protagonismo de esta prenda de vestir al describirla como "calzones marcadores del sitio donde se escondía el supuesto tesoro”, presentándolos como medio probatorio o seña legal hasta que la justicia fallara que Sosa Vergaray era el dueño legítimo.

Para variar el nivel narrativo Palma introduce diálogos como recurso para hacer hablar a los personajes y enunciar nuevas acciones:

- iEstá usted loco compadre- le dijo Urdanivia-, proponiéndome ir de día a sacar el entierro! ¿No sabe usted que la huaca huye con el sol? Espere usted siquiera a las siete de la noche, y cuente conmigo para acompañarlo.

- Tiene usted razón, compadre- contestó Sosa Vergaray-, y que Dios le pague su buen consejo. Lo dejaremos para esta noche. (Ibídem).

Intrascendente, en apariencia, es este diálogo entre Sosa Vergaray y su vecino Antonio Urdanivia a quienes Palma los hace compadres, después de haberle confiado sobre el supuesto tesoro, "que nunca lo hubiere hecho"; expresa sin embargo en boca de uno: la creencia de los buscadores y desenterradores de tesoros de que la huaca huye y es mejor desenterrarla en la noche; y en boca del otro, la ingenuidad y excesiva confianza.

Pero el genio literario de Palma lo apreciamos al incluir al gobernador y darle protagonismo en su rol de autoridad. En los sucesos descritos en la carta apenas se le menciona y se describe su actuación; sin embargo, para un escritor humorista como Palma no podía escapársele esta pincelada dentro de la tradición, no solo para darle variedad sino para enriquecer la representación 
de la realidad social con personajes, acontecimientos, ámbitos y atmósferas. De modo que, ordenando los niveles de autoridad en materia política y judicial, lo implica en el conflicto del supuesto tesoro, desprendiendo su intromisión de la desconfianza de Urdanivia, el tercer protagonista de los hechos, quien llevó hasta el gobernador el cumplimiento de la promesa que hicieron con Príncipe, de compartir el tesoro en partes iguales.

Pero fue el caso que también al gobernador se le despertó la gazuza y dijo que a la autoridad tocaba antes realizar una inspección ocular y percibir los quintos que, según la ley tantos, artículo cuantos, de la Recopilación de Indias, correspondían al rey... (Ibíd., p. 930).

La presentación e inclusión de la autoridad en el lío la ofrece con una frase precisa y cargada de humor irónico que fotografía la imagen de nuestras autoridades: "se le despertó la gazuza", y en el marco de las connotaciones de esta frase tan castiza, narra las actuaciones desatinadas y necias del gobernador: decidir hacer una inspección ocular so pretexto de "percibir los quintos" del rey, alegando leyes; argüir que el asunto era contencioso y que ahí estaba él para tomar posesión del tesoro en nombre del rey; contestar ante la amenaza con papel sellado y acudir hasta la Real Audiencia para referirse a lo que le hicieron los protagonistas: "Protesten ustedes hasta la pared de enfrente, pero yo saco el tesoro"; la intención de hacerlo si es que los vecinos no lo hubieran amenazado con darle "una paliza viva y efectiva", es una "amenaza más poderosa y convincente que mil resmas de papel sellado"; y, finalmente, la resolución de que los calzones quedarán en el sitio hasta que la justicia fallase, pues hubo pleito "que duró tres años" (según la carta, dos lustros).

Desde luego, Palma aprovecha el espacio narrativo para completar la pintura y emprenderlas contra el laberíntico poder judicial y, siguiendo la lógica de los juicios, afirmar que 
fue solventado a costa de la venta de los terrenos de ambos contrincantes "con pacto de retroventa" para "dar de comer al abogado, al procurador, al escribano y demás jauría tribunalicia”, cuyo fallo irrisorio suscita risa pues determinó a la postre que

Sosa Vergaray era dueño de sus calzones y que podía llevárselos y que Príncipe era dueño de la huaca o cerrillo, y era árbitro de dejarlo en pie o convertirlo en adobes. (Ibídem).

Que el fallo judicial fue así o no, jamás lo sabremos; en todo caso, no está lejos de los actuales fallos que nuestra justicia emite, precariedad que Palma describe socarronamente.

Los datos de la carta que Palma toma y eleva a la altura de su estilo, son justos aquellos que necesita para los finales de las tradiciones de tesoros enterrados y de desenterradores: Juan Príncipe, después de celebrar la victoria judicial con una pachamanca en la que gastó todos sus reales y aún quedó endeudado, fue en busca del tesoro. Palma pregunta y se responde:

¿Y sacó el tesoro? iClarinete! iVaya si lo sacó!

En la huaca no halló ni siquiera objetos curiosos de cerámica incásica, si no varias momias de gentiles. (Ibídem). 


\section{Conclusiones}

1. La búsqueda, hallazgo y exhibición de las cartas, permiten ampliar, enriquecer y valorar la vida y, en especial, la obra, del Patriarca de nuestra literatura. Ahora contamos con dos cartas más que incrementan su voluminosa correspondencia; dos fuentes escritas sobre las cuales elaboró dos Tradiciones cuyos temas se ambientan en la Región de La Libertad, en la ciudad histórica de Huamachuco. Asimismo, dos informantes, naturales ambos de esa ciudad, y don Nicolás Rebaza Cueto y don Manuel Moreno Azcate, este último recién conocido y de quien hace falta recoger algunos datos de su biografía para precisar las circunstancias en que se conocieron y entablaron correspondencia con el Maestro.

2. Los temas de los relatos de ambas cartas fueron dignos de ser elegidos por Palma y elevados a una obra de arte literaria, a una Tradición. Confirman, por un lado, el proyecto nacional del trabajo literario de Ricardo Palma de representar en lo posible al Perú, no solo en los hechos sociales y humanos de sus gentes sino de regiones y de tiempos históricos, a través de tres siglos. A su vez, al ser confrontados con sus fuentes, los textos literarios de Los Brujos de Shulcahuanga y Los buscadores de entierros evidencian el genio de Palma y la forma en que logra la creación de un género único, combinando el hecho histórico y la ficción a través de un lenguaje castizo, popular y bien pulimentado, cargado de humor satírico, irónico y jocoso.

3. La exégesis efectuada al texto Los brujos de Shulcahuanga -una de las más conocidas y tratadas por su tema histórico-, considerando su fuente escrita (cada “apuntación” que le hace llegar Rebaza Cueto en su carta), nos permite apreciar que los hechos narrados han sido presentados como una sublevación preindependentista, cuyas significaciones 
culturales e históricas, emanadas de la crítica, desdicen los enjuiciamientos que se han vertido sobre dicha tradición y sobre el propio Palma, especialmente por parte de Isabel Tauzin Castellanos. El tratamiento de este asunto será abordado en otra oportunidad con la debida amplitud y rigurosidad pues desborda los alcances de la presente ponencia.

\section{Bibliografía}

Bazán, D. (2001). Mujeres, ideas y estilo en las tradiciones de Palma. Lima: Editorial Universitaria de la Universidad Ricardo Palma.

Carbajal, A. (2015). Cartas de Nicolás Rebaza a Ricardo Palma. Huancayo: Nictálope Editores SAC.

Castillo Sánchez, W. (2012). Sartenazos que duelen o tiznan. Tradiciones de Ricardo Palma de la Región La Libertad. Trujillo: Editorial CEA.

Huárag Álvarez, E. (2004). Estructuras y Estrategias Narrativas en las Tradiciones Peruanas de Ricardo Palma. Lima: Universidad Ricardo Palma.

Palma, R. (1961). Tradiciones Peruanas Completas. (Cuarta Edición a cargo de Edith Palma). Madrid: Aguilar

Palma, R. (2005). Epistolario General (1846-1891), Tomo VIII, Vol. $1^{\circ}$. Lima: Editorial Universitaria de la Universidad Ricardo Palma.

Peña Rebaza, L. (2016). José Faustino Sánchez Carrión. Mi vida por la Independencia. Lima: Centro de Estudios Históricos y Sociales Huamachuco-CEG (Coedición). 
Sagermann Bustinza, L. (2015). Las Tradiciones de Ricardo Palma como crónica de la peruanidad. Lima: Editorial Universitaria de la Universidad Ricardo Palma.

Tanner, R. L. (2005). El humor de la ironía y la sátira en las Tradiciones Peruanas. Lima: Editorial Universitaria de la Universidad Ricardo Palma.

Discursos de incorporación. (1998-1999). Aula Palma I. Lima: Centro de Investigación de la Universidad Ricardo Palma.

Recibido: 4 de noviembre 2016 Aprobado: 2 de diciembre 2016 